\title{
Length-weight Relationship and Growth Pattern of Common Carp (Cyprinus Carpio Var. Communis) in Different Pond Environment in Mid Hill Region
}

\author{
P. Kumar*, N.N. Pandey, N.Okendro Singh¹, N. Chandra², D.C. Mishra², P.K. Agrawal'2, \\ A. Barat and J.C. Bhatt ${ }^{2}$ \\ Directorate of Coldwater Fisheries Research (ICAR), Bhimtal-263 136, Nainital (Uttarakhand) \\ ${ }^{1}$ College of Agriculture, Central Agricultural University, Iroisemba - 795 004, Imphal, Manipur \\ 2 Vivakanand Pravatiya Krishi Anusandhan Sansthan (VPKAS), Almora (Uttarakhand)
}

\begin{abstract}
An experiment on rearing of common carp was carried out in three types of ponds viz. earthen pond, cemented tank and poly tank at field centre, DCFR, Champawat (Uttarakhand) and at selected farmers field of Champawat District to evaluate the growth performance of this fish species. ANCOVA results revealed that there are three distinct seasons which influence on length-weight relationship of common carp culture in these pond systems. The fish follows isometric growth in spring season (March-May); (however it does not follow in the remaining seasons). Further, there is no specific growth pattern of common carp observed in these pond environment. Logistic curve is the best fitted model to the dataset obtained from cemented pond. However, Richards and von-Bertalanffy curves are found appropriate to represent the growth pattern of this fish in earthen and poly tank, respectively. In the long run, higher growth of fish is predicted in poly tank.
\end{abstract}

Keywords: Poly tank, Formulated diet, Length-weight relationship, Isometric growth.

\section{Introduction}

Fish is the cheapest source of protein in hilly region as well as an alternate source of income. Moreover, fish culture in hills encourages conserving the water and indigenous biodiversity. Common carp (Cyprinus carpio, communis) is one of the oldest cultured and most domesticated fish in the world. The common carp presently grown in India originated from two introductions, first in 1939 (German strain) and second in 1957 (Bangkok strain). Common carp is the main species of coldwater aquaculture. The culture of this fish species has gained many advantages for livelihood and commercial purposes because of its fast growth, high tolerance and easiness to handle, ability to be raised in high density in water volume, acceptability of wide range of feeds. In temperate aquaculture, the approach of mixed farming using indigenous and exotic carps is not yet reported however, the monoculture of common carp is practiced in different Himalayan states as well as in the uplands of Deccan plateau. In the upland waters the Indian major carps do not grow well due to the low thermal regime. Therefore, Chinese carps are taken as the candidate species for mixed culture in mid hilly area of Uttarakhand state. Performance of common carp culture was evaluated in monoculture and polyculture systems in the cemented ponds of the experimental fish farm, DCFR, Champawat (Tyagi and Behl, 1998; Tyagi et al., 1999). However, carp culture in different pond environments is not yet on record. As the temperature is one of the most important parameter for growth of any fish species, different pond systems which may encompass fluctuations in temperature needs to be studied in depth. Thus, in the present investigation, three different pond environments viz. cemented 
pond, earthen pond and poly tank (polythene lined earthen pond) were considered to study the growth performance of common carp.

The mathematical relationship between length and weight of the growing fish has great significance with regard to their morphology, biology and growth rate. Natarajan et al. (1977) reported the difference between length-weight relationships of intra-specific populations inhabiting the same water body. Several biological factors like sex (Reddy, 1981), size of the fish (Devraj, 1973), physiological condition and gonad maturity (Le Cren, 1951; Bashirullah, 1975), feeding (Reddy, 1981) and fatness have significant influence over length-weight relationship of fish. Different seasons may also influence this relationship. There is no information on influence of season while establishing the length-weight relationship of common carp in captive condition. Further, we have seen plenty of work related to growth study of common carp however, in most of the cases, the researchers mainly concentrated only on finding of either length or weight, or both at some age interval of the fish. Based on the incremental value of length or weight between the age intervals, growth structure of this fish species is defined. The present investigation aims to find out a comprehensive length-weight relationship and growth pattern of common carp in pond environments, which can be directly used in fishery assessment.

\section{Materials and Methods}

\section{Data Collection}

A field trial experiment was conducted for rearing of common carp in three different pond systems viz. earthen ponds, cemented pond and poly tank (polythene lined) having size of about $100 \mathrm{sq} \mathrm{m}$ with an average depth of $1.5 \mathrm{~m}$ in triple replication, at field centre, DCFR, Champawat (Uttarakhand) and at selected farmer's field of Champawat district at mid altitude area of Uttarakhand (1670 -1800 m asl). The experiment was conducted during the period March 2008 to February 2009 under monoculture system.
Stocking density (2 fish/sq $\mathrm{m}$ ), food and feeding and other intercultural activities were similar for all the tanks. Length and weight of the fish was taken on monthly basis (a sample size of 30 specimens from each pond were randomly selected). All data were pooled in four groups according to different seasons (season 1-Spring: March-May, season 2-Summer: JuneAugust, season 3-Autumn: September-November and season 4-Winter: December-February) to develop a comprehensive length-weight model of this fish species. The specimens of this fish species ranged $33-220 \mathrm{~mm}$ in length and 2-207 gm in weight. Monthly average length of common carp was also separately observed for each pond/ tank to study its growth pattern (presented in Table 1). Data was analyzed by using SPSS 12.01.

\section{Length-Weight Model}

In general, the change in weight of fish with respect to its length is described by the equation:

$$
W=a L^{b}
$$

where ' $W$ ' is the observed fish weight, ' $L$ ' is the observed fish length and ' $a$ ' and ' $b$ ' are the parameters to be estimated. Also, the linearized form of equation is obtained by taking logarithmic transformation on both sides of the above equation, as

$$
\log W=\log a+b \log L
$$

The analysis of covariance (ANCOVA) is a combination of analysis of variance and regression analysis. ANCOVA is most commonly applied in fisheries to check if the regression lines for the groups are parallel. If there is evidence that the individual regression lines are not parallel, then a separate regression line must fit for each group for prediction purposes.

\section{Growth Models}

Denoting the 'size' of a fish ('size' can refer to standard length, body weight, etc.) by $L_{t}$ at a particular age of $t$. Let, 
$\mathbf{L}^{\infty}=$ Asymptotic fish size; $\mathbf{K}=$ Growth coefficient (per month); $\mathbf{t}=$ Age (in months); $\mathbf{t} 0=$ Theoretical age (in months) when fish was size zero; $\mathbf{b}=$ Added parameter in Richards model.

Then, the most commonly available growth models in fisheries are given below:

Logistic Growth Model

$$
L_{t}=L_{\infty}\left[1+e^{-K\left(t-t_{0}\right)}\right]^{-1}
$$

\section{Gompertz Growth Model}

$$
L_{t}=L_{\infty} \exp \left\lceil-\exp \left\{-K\left(t-t_{0}\right)\right\}\right\rceil
$$

Von-Bertalanffy Growth Model by

$$
L_{t}=L_{\infty}\left[1-e^{-K\left(t-t_{0}\right)}\right]
$$

Richards Growth Model

$$
L_{t}=L_{\infty}\left[1+b e^{-K\left(t-t_{0}\right)}\right]^{-1 / b}
$$

In the above growth model equations, the unknown parameters, viz. $\mathrm{L}_{\infty}, \mathrm{K}, \mathrm{b}$ and $\mathrm{t}_{0}$ have biological meanings. It is also worth highlighting that small fast growing fish species are characterize by large $K$ and small $L_{\infty}$ values while long-lived slow growing species have small $K$ and larger $L_{\infty}$ values.

For deciding best-fitted models, the coefficient of determination, $\mathrm{R}^{2}$ and mean square error (MSE) are generally used.

$$
\begin{gathered}
R^{2}=1-\frac{\sum_{t=1}^{n}\left(L_{t}-\hat{L}_{t}\right)^{2}}{\sum_{t=1}^{n}\left(L_{t}-\bar{L}\right)^{2}} \\
\mathrm{MSE}=\left[\sum_{t=1}^{n}\left(L_{t}-\hat{L}_{t}\right)^{2} / n\right\rceil
\end{gathered}
$$

where,

$L_{t} \quad$ Fish Length of $\mathrm{t}^{\text {th }}$ observation;

\section{$\bar{L} \quad$ Average Fish Length;}

$\hat{L}_{t} \quad$ Predicted fish Length of tth observation;

$\mathrm{n} \quad$ Number of observations, $t=1,2, \ldots, n$.

The better model will have the least value of MSE and larger value of $R^{2}$.

\section{Results and Discussion}

The results of the analysis of covariance (ANCOVA) are presented in Table 2, which shows that seasonal effect on length-weight relationship of common carp is highly significantly different $(F$ calculated value $=105.834$, $\mathrm{p}<0.01)$ in the temperate climate of the mid hills. The regression lines due to different seasons are further examined in detail. Since the seasons 3 and 4 are not significantly different at $5 \%$ level of significance, they are combined together and slope of this regression line is further compared with seasons 1 and 2 separately, the corresponding tests were highly significant different at the critical level as shown in Table 2. Thus, we can say that there are three distinct seasons viz. season-I: Spring (March-May), season-II: Summer (June-August) and season-III: Autumn and Winter (September-February) regarding length-weight relationship of common carp in the present culture systems.

The allometric model and its linearized form given by equations (1) and (2) were fitted using Levenberg-Marquardt and least squares method respectively to the datasets of three different seasons, separately. The estimates of parameter, other information of the fitted models are presented in Table 3. KolmogorovSmirnov (K-S) test $p$-values show that the fitted models do not follow normality assumption (Table 3). However, normality assumption is not so stringent for fitting of nonlinear models but it must strictly follow for linear and linearized models. Thus, the fitted nonlinear models are chosen as the appropriate length-weight models in this case. Further, to check the isometric 
growth of the fish, a null hypothesis $\mathrm{H}_{0}: \mathrm{b}=3$ is tested against $H_{1}: b \neq 3$. The corresponding t-test statistics have been calculated for seasons I, II and III respectively. The fish growth does not follow isometric growth in seasons II and III. However, the calculated value of the statistic for season I is 0.479 which is

Table 1 Observed average values of length in $\mathrm{mm}$ from different pond systems.

\begin{tabular}{|l|c|c|c|}
\hline \multicolumn{1}{|c|}{ Month } & $\begin{array}{c}\text { Cemented } \\
\text { pond }\end{array}$ & $\begin{array}{c}\text { Earthen } \\
\text { pond }\end{array}$ & Poly tank \\
\cline { 2 - 4 } & $\begin{array}{c}\text { Average } \\
\text { length in } \\
\text { (mm) }\end{array}$ & $\begin{array}{c}\text { Average } \\
\text { length in } \\
\text { (mm) }\end{array}$ & $\begin{array}{c}\text { Average } \\
\text { length in } \\
\text { (mm) }\end{array}$ \\
\hline March 2008 & 69.355 & 36.667 & 36.667 \\
\hline April 2008 & 88.258 & 48.400 & 72.833 \\
\hline May 2008 & 100.323 & 69.833 & 88.433 \\
\hline June 2008 & 106.839 & 90.767 & 104.700 \\
\hline July 2008 & 123.839 & 108.967 & 122.033 \\
\hline August 2008 & 130.968 & 125.100 & 141.333 \\
\hline September 2008 & 140.839 & 137.833 & 157.433 \\
\hline October 2008 & 147.032 & 153.833 & 168.233 \\
\hline November 2008 & 152.065 & 157.567 & 183.467 \\
\hline December 2008 & 156.935 & 168.900 & 190.833 \\
\hline January 2009 & 160.065 & 176.200 & 197.267 \\
\hline February 2009 & 159.258 & 175.767 & 211.233 \\
\hline
\end{tabular}

less than the critical value 1.96 at $5 \%$ level of significance for large sample size say, $>50$. Thus, fish follows isometric growth in season I. Moreover, the graphs of fitted models along with observed values are shown in Figure 1, 2 and 3 for seasons-I, II and III respectively. The fish is healthier in the spring season as compared to other seasons. Thus, spring season favors good health and growth of common carp in the coldwater aquatic conditions.

Four different growth curves namely, logistic, Gompertz, von-Bertalanffy and Richards models were fitted using Levenberg-Marquardt method to the dataset of age (month)-at-

Table 2 Analysis of covariance (ANCOVA) in lengthweight relationship for different seasons of common carp.

\begin{tabular}{|l|c|l|}
\hline \multicolumn{1}{|c|}{ Seasons } & p-value & \multicolumn{1}{c|}{ Comment } \\
\hline 1 v/s 2 & $<0.01$ & Highly significant \\
\hline 1 v/s 3 & $<0.01$ & Highly significant \\
\hline 1 v/s 4 & $<0.01$ & Highly significant \\
\hline 2 v/s 3 & $<0.01$ & Highly significant \\
\hline 2 v/s 4 & $<0.01$ & Highly significant \\
\hline 3 v/s 4 & 0.474 & Not significant \\
\hline 1 v/s 3 \& 4 & $<0.01$ & Highly significant \\
\hline 2 v/s 3 \& 4 & $<0.01$ & Highly significant \\
\hline
\end{tabular}

Predictors: (Constant), logl and Dependent Variable: logw.

Table 3 Fitting of length-weight models for different seasons of common carp.

\begin{tabular}{|l|c|c|c|c|c|c|}
\hline \multirow{2}{*}{ Model information } & \multicolumn{2}{|c|}{ Season I } & \multicolumn{2}{c|}{ Season II } & \multicolumn{2}{c|}{ Season III } \\
\cline { 2 - 7 } & Linearized & Nonlinear & Linearized & Nonlinear & Linearized & Nonlinear \\
\hline \multirow{2}{*}{ log a/ a } & -3.927 & $6.182 \times 10^{-5}$ & -2.694 & $6.067 \times 10^{-3}$ & -1.015 & 0.109 \\
& $(0.107)$ & $\left(1.34 \times 10^{-5}\right)$ & $(0.049)$ & $\left(6.06 \times 10^{-4}\right)$ & $(0.007)$ & $(0.002)$ \\
\hline \multirow{2}{*}{ b } & 2.816 & 2.977 & 2.217 & 1.988 & 1.426 & 1.403 \\
& $(0.059)$ & $(0.048)$ & $(0.024)$ & $(0.021)$ & $(0.003)$ & $(0.003)$ \\
\hline R-square & 0.893 & 0.970 & 0.970 & 0.975 & 0.998 & 0.998 \\
\hline MSE & 0.024 & 10.222 & 0.001 & 12.549 & 0.001 & 1.375 \\
\hline K-S Test p-value & $<0.01$ & $<0.01$ & $<0.01$ & $<0.01$ & $<0.01$ & $<0.01$ \\
\hline
\end{tabular}


Table 4 Fitting of growth models for common carp from different pond systems.

\begin{tabular}{|c|c|c|c|c|}
\hline Model information & Logistic & Gompertz & Von-Bertalanffy & Richards \\
\hline \multicolumn{5}{|c|}{ Cemented pond } \\
\hline $\mathrm{L}_{\infty}$ & 167.218 & 172.290 & 181.813 & 167.918 \\
\hline K & 0.324 & 0.242 & 0.161 & 0.309 \\
\hline to & 1.894 & 0.539 & -1.975 & 1.702 \\
\hline b & - & - & - & 0.825 \\
\hline R-square & 0.995 & 0.995 & 0.994 & 0.995 \\
\hline MSE & 5.160 & 5.423 & 6.640 & 5.792 \\
\hline Run Test |Z| value & 0.115 & 0.115 & 0.000 & 0.115 \\
\hline \multicolumn{5}{|c|}{ Earthen pond } \\
\hline $\mathrm{L}_{\infty}$ & 182.068 & 193.906 & 236.116 & 188.140 \\
\hline K & 0.430 & 0.277 & 0.121 & 0.334 \\
\hline to & 4.159 & 3.030 & -0.125 & 3.540 \\
\hline$b$ & - & - & - & 0.371 \\
\hline R-square & 0.998 & 0.998 & 0.993 & 0.998 \\
\hline MSE & 6.741 & 5.753 & 19.694 & 5.524 \\
\hline Run Test |Z| value & 0.000 & 0.416 & 0.303 & 0.303 \\
\hline \multicolumn{5}{|c|}{ Poly tank } \\
\hline $\mathrm{L}_{\infty}$ & 217.334 & 233.702 & 286.325 & \multirow{7}{*}{$\begin{array}{l}\text { There is no optimum } \\
\text { solution. }\end{array}$} \\
\hline K & 0.363 & 0.235 & 0.105 & \\
\hline to & 4.309 & 3.061 & -0.467 & \\
\hline b & - & - & - & \\
\hline R-square & 0.990 & 0.994 & 0.996 & \\
\hline MSE & 37.322 & 23.279 & 13.113 & \\
\hline Run Test |Z| value & 0.208 & 0.416 & 0.416 & \\
\hline
\end{tabular}

length $(\mathrm{mm})$ of common carp observed from three different pond environments. Different sets of initial parameter values have been tried so that a global convergence criterion is met for fitting of nonlinear models. The estimates of parameters, $\mathrm{R}^{2}$, MSE and run test statistic $(|Z|)$ value for the above models are presented in Table 4. For the cemented pond, 


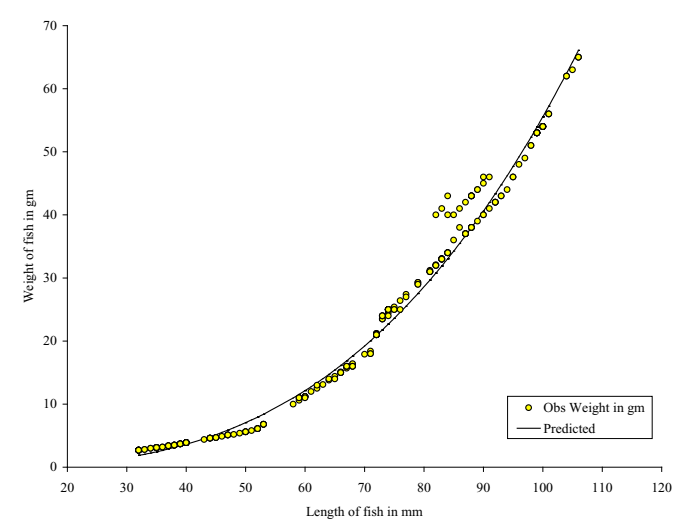

Fig. 1 Fitted length-weight model to the dataset of season-I.

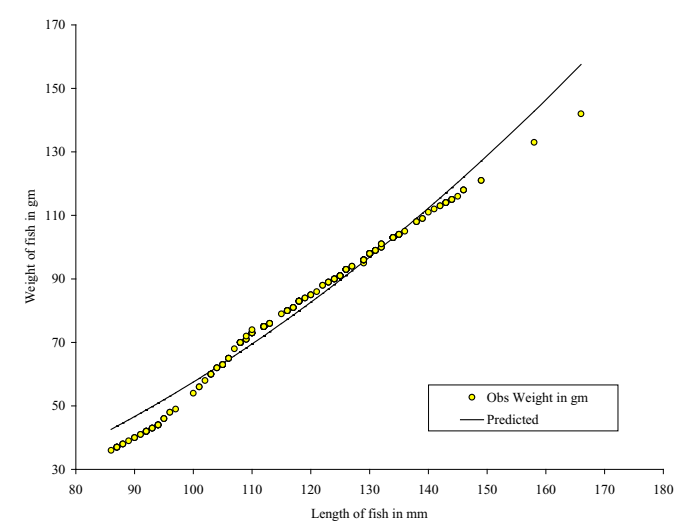

Fig. 2 Fitted length-weight model to the dataset of season-II.

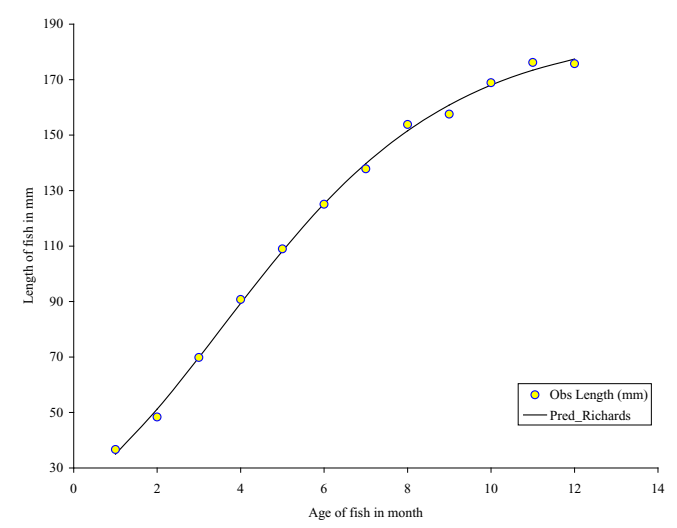

Fig. 5 Graphical display of observed and best-predicted growth by Richards model for common carp from earthen pond.

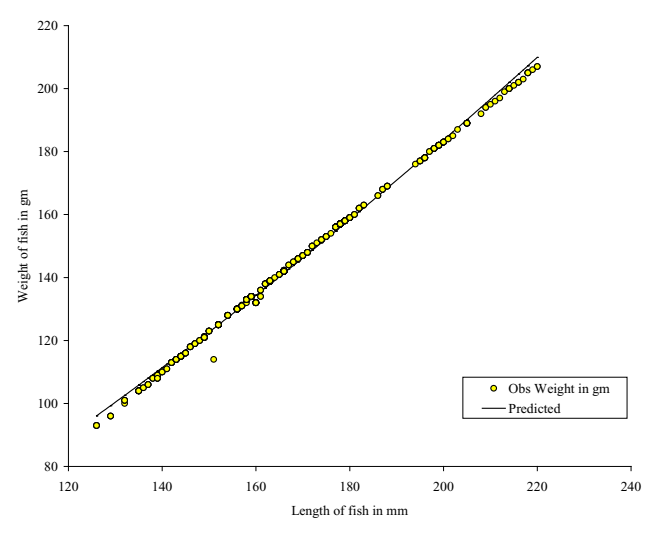

Fig. 3 Fitted length-weight model to the dataset of season-III.

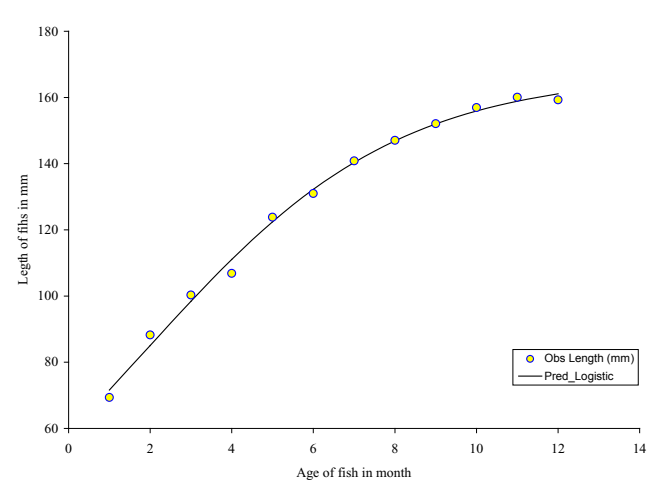

Fig. 4 Graphical display of observed and bestpredicted growth by logistic model for common carp from cemented pond.

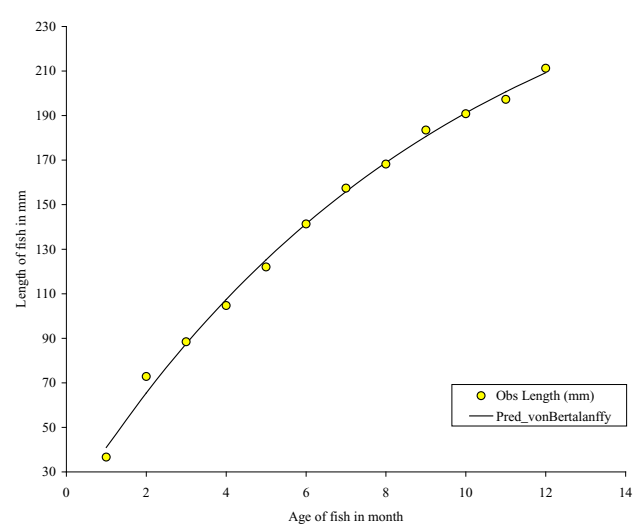

Fig. 6 Graphical display of observed and bestpredicted growth by von-Bertalanffy model for common carp from poly tank. 
logistic model shows better performance than other models when the criterion of MSE is used to identify the best-fit model since $\mathrm{R}^{2}$ values are approximately same in all the cases. The model adequacy of logistic growth curve along with observed values is depicted in Figure 4. Further, independence assumption about residuals is satisfied since the run test $|\mathrm{Z}|$ value $(0.115$ in Table 4$)$ is well below the critical value 1.96 of normal distribution at $5 \%$ level of significance. However, Richards and von-Bertalanffy curves are found appropriate to represent the growth pattern of this fish in earthen pond and poly tank respectively when the above criterion of best-fit model was used. Also, the model adequacy of Richards and von-Bertalanffy growth curves along with their observed values are depicted in Fig. 5 and 6 respectively. The results reveal that there is no any specific growth pattern of common carp in these pond environments. In the long run, higher growth of fish is predicted in poly tank, approximately $41 \%$ and $34 \%$ higher growth as compare to cemented and earthen ponds respectively. Thus, we conclude that poly tanks are more suitable ponds for raising common carps in captive condition. Spring season is the peak growth period for common carp. Production of common carp could be increased by intensifying the feeding practice during spring season.

\section{References}

Bashirullah, A.K.N. (1975) Biology of Lutjanus griseus (L) of the Cubagua Island, Venezuela, 1. Length weight, gut length relationship and condition factor. Biol. Inst. Oceanoger. Univ. Oriete, 14, 101-107.

Devraj, M. (1973) Biology of the large snakehead ophiocephalus marulius (Ham.) in bhawanisagar water. Ind J. Fish., 20, 280-307.

Le Cren, E.D. (1951) The length weight relationship and seasonal cycle in gonadal weight and condition in perch (Perca fluviatalis). J. Anim. Ecol., 20, 201-219.

Natarajan, A. V., Desai, V.R., Misra, D.N. and Srivastava, N.P. (1977) Some new light on the population ecology of the gangatic major carp Catla catla (Ham) from Rehand reservoir. Matsya, 3, 46-59.

Reddy, P.N. (1981) Length weight relationship in Channa punctatus (Bloch) from Guntur, Andhra Pradesh with a comparision of the relationship of the stock from Aligar and Guntur. Matsya, 7, 14-21.

Tyagi, B.C. and Behl, R. (1998) Growth and survival of cultivable carps at high altitude of Kumaon Himalayas under farm conditions. Fish. Gen. Biodiversity Conserv. NATCON Pub., 5, 331-338.

Tyagi, B.C., Bhanja S. K., Joshi K. D. and Basade Y. (1999) Development of an intensive culture system for Chinese carps in Himalayan uplands. In: Proc. Nat. Sem. Transfer Techno, 3-5 